\title{
Theoretical and experimental research of anti-tank kinetic penetrator ballistics
}

\author{
K. MOTYL ${ }^{1}$, M. MAGIER ${ }^{2}$, J. BORKOWSKI ${ }^{2}$, and B. ZYGMUNT ${ }^{1 *}$ \\ ${ }^{1}$ Faculty of Mechatronics and Aerospace, Military University of Technology, 2 Kaliskiego St., 00-908 Warsaw, Poland \\ ${ }^{2}$ Military Institute of Armament Technology, 7 Prymasa Stefana Wyszyńskiego St., 05-220 Zielonka, Poland
}

\begin{abstract}
A mathematical-physical model of the hypersonic anti-tank kinetic subcalibre projectile for 120 mm munition was built. Computer simulations of the projectile flight were performed for any angle of shooting, from $0^{\circ}$ to $90^{\circ}$. Trajectories of projectile flights were determined considering all angles of shooting. Theoretical calculations were verified by experimental measurement of the projectile velocity in time while shooting on a test range. Some conclusions with regard to safety during hypersonic projectile shooting on the test range were formulated.
\end{abstract}

Key words: hypersonic projectile, mathematical model, simulation of flight.

\section{Introduction}

Subcalibre anti-tank projectiles are a modern kind of artillery ammunition used for the destruction of heavy armoured fighting vehicles (e.g. troop carriers). Kinetic energy in the order of 10 MJ is delivered with an elongated metal rod, the so-called penetrator, made of a sintered tungsten or sintered uranium powders, having the mass of a few $\mathrm{kg}$ and a velocity of over 1500 $\mathrm{m} / \mathrm{s}$. The propulsion of the projectile to a hypersonic velocity is achieved in a gun barrel, due to the interaction of the combustion products of a propellant charge, i.e. due to powder gases under a maximum pressure of over $500 \mathrm{MPa}$. After hitting a target, the process of projectile penetration takes place (e.g. into a steel or composite tank armour). The penetrator's diameter is several times lower than the calibre of the gun barrel from which the penetrator is fired, and hence the projectile's name - subcalibre. A heavy penetrator moves in the barrel as a carrier integrated with so-called sabots, i.e. clamps made of lightweight metal (Al alloy) that drop off from the projectile when it leaves the barrel. Stable and straight-lined flight of the projectile is ensured by the fins fixed to the end of the penetrator [1-6]. A schematic of the subcalibre anti-tank projectile is shown in Fig. 1.

The development of subcalibre antitank projectiles was focused on increasing their velocity and slenderness, i.e. increasing the ratio of projectile length to its diameter $(l / d)$. At present, this parameter exceeds a value of 30 . In the literature, models and simulations are described that are related to the internal ballistics of the penetrator driven in a barrel, and external ballistics of the penetrator related to the initial phase of projectile flight (up to several $\mathrm{km}$ ) for an almost horizontal shot.

The hypersonic velocity of the projectile and its aerodynamic shape allow a significantly greater maximum range to be achieved. Thus, ensuring safety has become very important when subcalibre projectiles are fired. One possible solution is

\footnotetext{
*e-mail: bogdan.zygmunt@wat.edu.pl
}

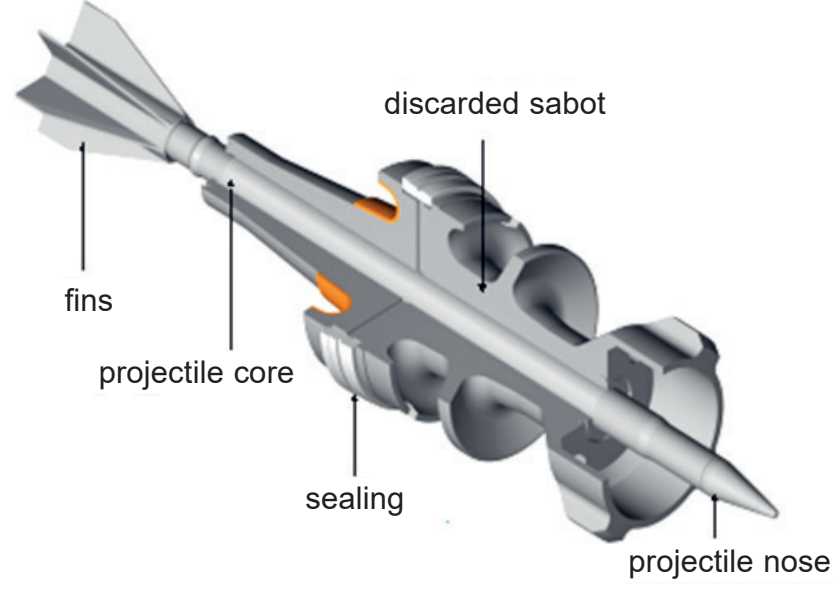

Fig. 1. Construction of a subcalibre anti-tank projectile

to apply self-destruction of the projectile by the separation of stabilisers, or its division into several parts after a few seconds of projectile flight. For projectiles that do not undergo fragmentation, it is necessary to know their maximum ranges, especially for the cases of unintentional firing at large angles.

Here, simulations of flight have been undertaken and trajectories have been determined for the angles of firing from $0^{\circ}$ (horizontal shot) to $90^{\circ}$ (vertical shot) for the developed mathematical-physical model of the subcalibre projectile. The initial data used for simulations were obtained from experimental measurements of the projectile velocity in time. The main goal is to assess the safety zones when shooting hypersonic subcalibre projectiles at military ranges.

\section{Physical model of subcalibre projectile}

To develop a physical model, the features of the object that have a significant influence on the analysed phenomena were 
considered [7-12]. First of all, to develop a physical model of the projectile, it was necessary:

1. To accept the coordinate systems that are necessary for the description of projectile movement and of the forces affecting it.

2. To determine the projectile structure, i.e.:

- geometrical characteristics;

- mass-inertia characteristics;

- tracer characteristic.

3. To determine the component external forces and moments of the forces affecting the projectile and the functions describing them, i.e.:

- gravitational force and its moment;

- aerodynamic force and its moment;

- Coriolis force and its moment;

- Magnus force and its moment.

4. The characteristics of the medium of the object's motion, i.e. density, viscosity, temperature, and pressure of air depending on the flight altitude were taken into consideration. The atmospheric model implemented in the computer program was the Normal Atmosphere of Artillery (NAA) [7].

Movement of both spin- and fin-stabilised projectiles is most frequently described using one- or three-degrees-of-freedom mathematical models that differ in the number of dependent variables and simplifications taken into consideration for the forces and aerodynamic moments acting on the projectile during its flight. A point mass trajectory model was built according to NATO STANAG 4355. This model with three degrees of freedom assumes that the projectile is perfectly stabilised on its flight trajectory, i.e. the projectile's axis follows the direction of its velocity vector. According to the principle of a momentum change, an equation of projectile movement in a system connected with the Earth can be written as follows [13]:

$$
\mathrm{m} \cdot \overrightarrow{\mathrm{u}}=\overrightarrow{\mathrm{DF}}+\mathrm{m} \cdot \overrightarrow{\mathrm{g}}+\mathrm{m} \cdot \vec{\Lambda}
$$

where:

$\overrightarrow{\mathrm{DF}}$ - negative acceleration caused by aerodynamic drag; $\mathrm{m}-$ projectile mass.

$$
\frac{\overrightarrow{D F}}{m}=-\left(\frac{\pi \cdot \rho \cdot i \cdot d^{2}}{8 \cdot m}\right) \cdot C_{D} \cdot v \cdot \vec{v},
$$

where:

$\mathrm{d}$ - diameter of projectile;

$\rho$ - air density;

$\mathrm{C}_{\mathrm{D}}$ - aerodynamic coefficiant;

$\mathrm{i}$ - matching factor.

$$
\vec{g}=-g_{0} \cdot\left(R^{2} / r^{3}\right) \vec{r}=-g_{0}\left[\begin{array}{r}
X_{1} / R \\
1-2 \cdot X_{2} / R \\
X_{3} / R
\end{array}\right]
$$

where:

$\overrightarrow{\mathrm{g}}$ - Earth acceleration;

$\mathrm{R}$ - Earth radius;

lat - latitude;

$\mathrm{X}_{1}, \mathrm{X}_{2}, \mathrm{X}_{3}$ - position of the projectile in space;

$$
\mathrm{g}_{0}=9.80665[1-0.0026] \cdot \cos (2 \cdot \mathrm{lat}) ;
$$

$\vec{\Lambda}-$ acceleration caused by Coriolis force:

$$
\vec{\Lambda}=-2(\vec{\omega} \times \vec{u})
$$

$\overrightarrow{\mathrm{v}}$ - relative velocity of projectile;

$\overrightarrow{\mathrm{u}}$ - velocity of projectile;

$\overrightarrow{\mathrm{w}}-$ wind velocity;

$$
\overrightarrow{\mathrm{v}}=\overrightarrow{\mathrm{u}}-\overrightarrow{\mathrm{w}}
$$

$\vec{\omega}-$ vector of Earth angular velocity:

$$
\vec{\omega}=\left[\begin{array}{c}
\Omega \cdot \cos (\text { lat }) \cdot \cos (\mathrm{AZ}) \\
\Omega \cdot \sin (\text { lat }) \\
-\Omega \cdot \cos (\text { lat }) \cdot \sin (\mathrm{AZ}
\end{array}\right] .
$$

\section{Scalar form of equations of projectile motion}

A scalar form of equations of projectile movement is obtained by projection of the vector equation on the axes of the Earth coordinate system. Such designed mathematical model is a system of differential-algebraic equations, among which one can distinguish:

- dynamic equations of motion of projectile mass center:

$$
\begin{aligned}
\frac{d u_{1}}{d t} & =-\left(\frac{\pi \cdot \rho \cdot i \cdot d^{2}}{8 \cdot m}\right) \cdot C_{D_{0}} \cdot v \cdot v_{1}-g_{0} \cdot \frac{X_{1}}{R} \\
& +-2 \Omega\left(\sin (\text { lat }) \cdot u_{3}+\cos (\text { lat }) \cdot \sin (A Z) \cdot u_{2}\right)
\end{aligned}
$$

$$
\begin{aligned}
\frac{d u_{2}}{d t} & =-\left(\frac{\pi \cdot \rho \cdot \mathrm{i} \cdot \mathrm{d}^{2}}{8 \cdot \mathrm{m}}\right) \cdot \mathrm{C}_{\mathrm{D}_{0}} \cdot \mathrm{v} \cdot \mathrm{v}_{2}-\mathrm{g}_{0}\left(1-\frac{2 \mathrm{X}_{2}}{\mathrm{R}}\right) \\
& +2 \Omega\left(\cos (\text { lat }) \cdot \sin (\mathrm{AZ}) \cdot \mathrm{u}_{1}+\cos (\text { lat }) \cdot \cos (\mathrm{AZ}) \cdot \mathrm{u}_{3}\right)
\end{aligned}
$$

$$
\begin{aligned}
\frac{d u_{3}}{d t} & =-\left(\frac{\pi \cdot \rho \cdot i \cdot d^{2}}{8 \cdot m}\right) \cdot C_{D_{0}} \cdot v \cdot v_{3}-g_{0} \cdot \frac{X_{3}}{R} \\
& +-2 \Omega\left(\cos (\text { lat }) \cdot \cos (A Z) \cdot u_{2}-\sin (A Z) \cdot u_{1}\right)
\end{aligned}
$$

- kinematic equations of projectile mass center motion:

$$
\begin{aligned}
& \frac{\mathrm{dX}_{1}}{\mathrm{dt}}=\mathrm{u}_{1} \\
& \frac{\mathrm{dX}_{2}}{\mathrm{dt}}=\mathrm{u}_{2} \\
& \frac{\mathrm{dX}}{\mathrm{dt}}=\mathrm{u}_{3}
\end{aligned}
$$


- algebraic additional equations:

$$
\begin{gathered}
\mathrm{v}_{1}=\mathrm{u}_{1}-\mathrm{w}_{1} \\
\mathrm{v}_{2}=\mathrm{u}_{2}-\mathrm{w}_{2} \\
\mathrm{v}_{3}=\mathrm{u}_{3}-\mathrm{w}_{3} \\
\mathrm{v}=\sqrt{\mathrm{v}_{1}^{2}+\mathrm{v}_{2}^{2}+\mathrm{v}_{3}^{2}}
\end{gathered}
$$

\section{Results of computer simulation of the projectile flight for small angles of shooting}

Using the developed mathematical-physical model of a hypersonic projectile, a computer simulation was performed, and the basic parameters of the projectile trajectory were determined. Firing with subcalibre projectiles is performed as "direct fire", i.e. at very small angles of $\pm 3^{\circ}$. Thus, in practice, it is the case of the so-called horizontal throw. The initial data of the designed simulation computer program for the examined hypersonic projectile are listed in Table 1.

For the simulation of the projectile flight, it is necessary to know how the aerodynamic coefficient depends on the velocity of the studied object. Such dependence for the projectile under study was determined using PRODAS [14], a commercial aerodynamics program.

Table 1

Chosen parameters of a projectile under study

\begin{tabular}{|c|c|c|}
\hline No. & Parameter & Value \\
\hline 1. & Projectile mass & $3.65 \mathrm{~kg}$ \\
\hline 2. & Initial velocity & $1670 \mathrm{~m} / \mathrm{s}$ \\
\hline 3. & Diameter & $0.0244 \mathrm{~m}$ \\
\hline 4. & Characteristic area of cross-section & $4.676 \cdot 10^{-4} \mathrm{~m}^{2}$ \\
\hline 5. & Air density & $1.225 \mathrm{~kg} / \mathrm{m}^{3}$ \\
\hline 6. & Air temperature & $15^{\circ} \mathrm{C}$ \\
\hline 7. & Air pressure & $1013.25 \mathrm{hPa}$ \\
\hline 8. & Wind & $0 \mathrm{~m} / \mathrm{s}$ \\
\hline 9. & Gravity acceleration & $9.80655 \mathrm{~m} / \mathrm{s}^{2}$ \\
\hline 10. & Angle of the shooting & $0 \div 90^{\circ}$ \\
\hline 12. & Coordinates of a cannon, $\mathrm{X}_{1}, \mathrm{X}_{2}$ & $0,0 \mathrm{~m}$ \\
\hline
\end{tabular}

Exemplary simulation results, generated with MATHCAD for the flight of the hypersonic projectile fired at small angles, are presented graphically in Figs. 2-4.

It can be seen from the diagrams in Fig. 3, that for firing angles larger than $1^{\circ}$ the calculated projectile range is over 10 $\mathrm{km}$. Such range can pose a serious threat for the environment when subcalibre projectiles are fired on artillery ranges. From

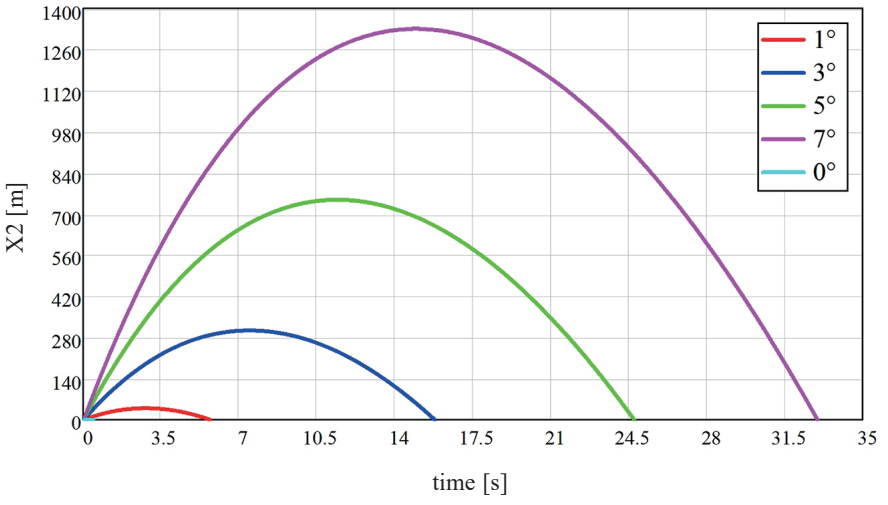

Fig. 2. Height of the projectile flight vs. time for small angles of shooting

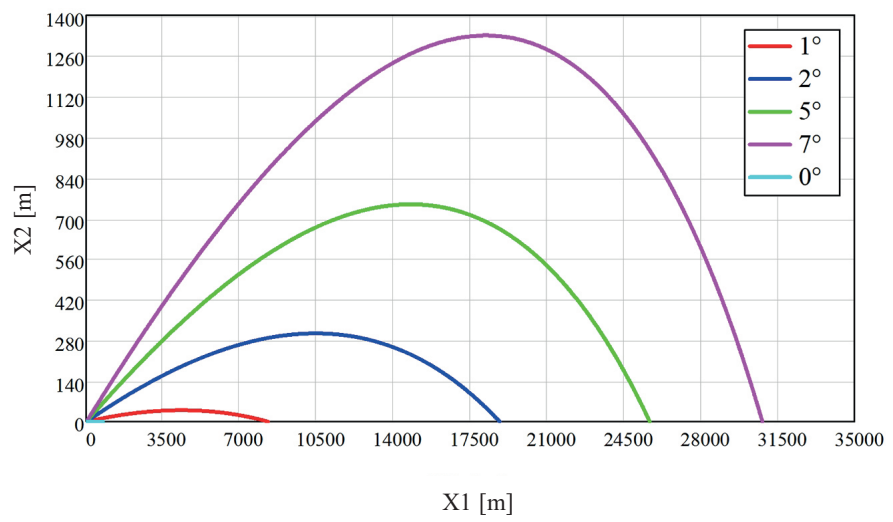

Fig. 3. Flight trajectories of projectiles for small angles of shooting

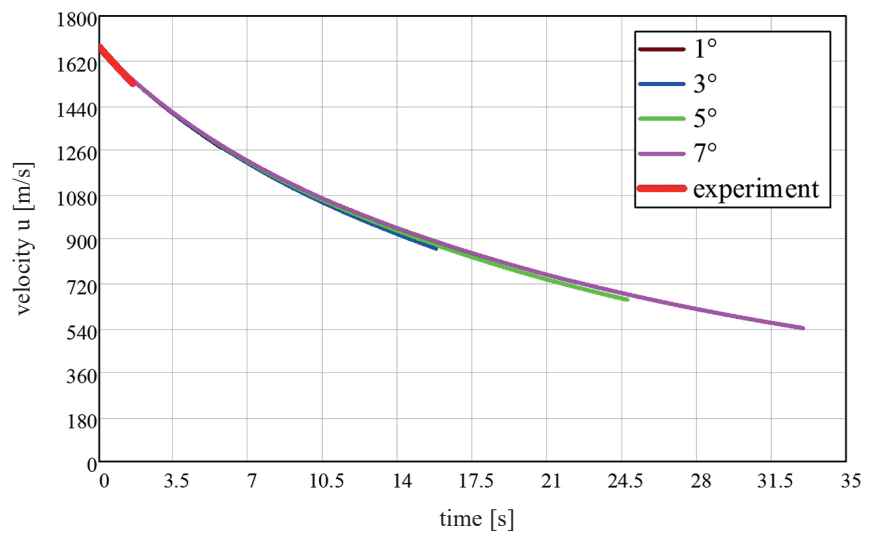

Fig. 4. Projectile velocity vs. time for small angles of shooting

Fig. 4, for the examined hypersonic projectiles firing at small angles, this parameter does not influence the projectile velocity, because it shows a mono-tonic decrease with distance from the barrel outlet to the drop on the Earth's surface.

To verify the developed theoretical model of the hypersonic projectile, continuous measurement of the projectile velocity was made on the initial segment of its flight, equal to $2550 \mathrm{~m}$ (i.e. the distance between the barrel's outlet and the target). 


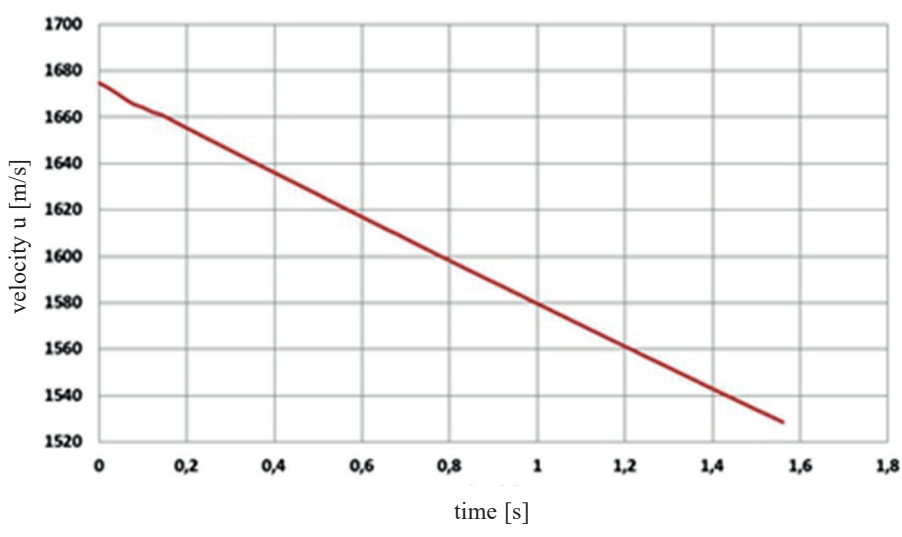

Fig. 5. Experimentally measured dependence of projectile velocity vs. time in the initial section of flight $(0-2,5 \mathrm{~km})$

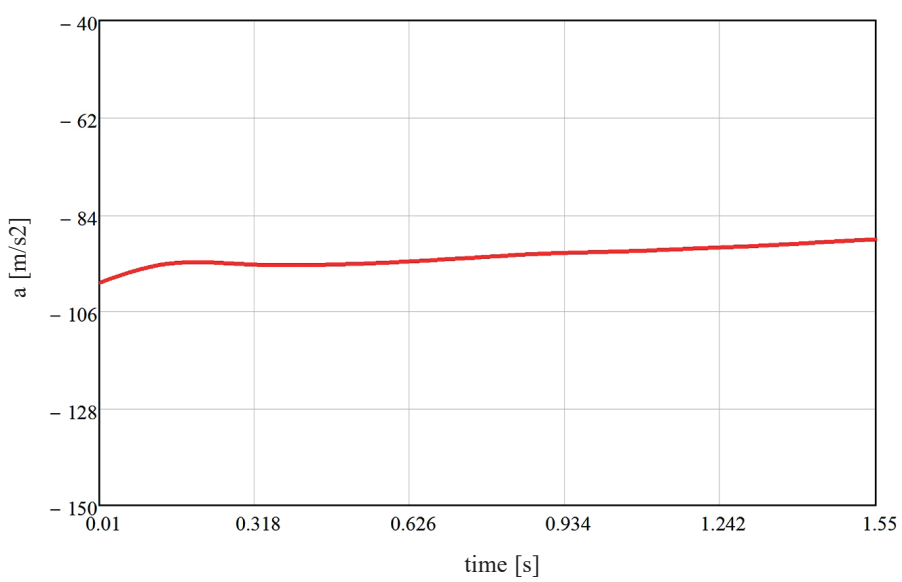

Fig. 6. Negative acceleration of the projectile determined the from experimental dependence $u=f(t)$ presented in Fig. 5
The shot angle was practically $0^{\circ}$ (i.e. the so-called horizontal shot), and the height of the cannon mouth was $2,5 \mathrm{~m}$. For continuous measurement of the projectile velocity, a Weibel-made Doppler radar with an SL 30031 antenna was used. The obtained experimental results are shown in Figs. 4 and 5, where they can be compared with the dependencies of projectile velocity with time, which were determined theoretically. The dependence of the negative acceleration with time for the projectile is presented in Fig. 6. This figure was determined from the experimentally measured dependence $u=f(t)$ shown in Fig. 5. The data consistency of the theoretical and experimental relationships is acceptable, being in the order of $5 \%$ (Fig. 4), which verifies the correctness of the developed theoretical model of the hypersonic projectile during the initial phase of flight.

\section{Results of computer simulation of projectile flight for large angles of shooting}

Determination of the approximate range and ceiling for hypersonic subcalibre projectiles is significant because of the safety assurance for people and objects in the area of exploited artillery grounds. It is therefore necessary to predict rebounding shots (ricochets) or accidental projectile firing at large angles. Using the methodology applied in Sections 2-4, experimentally verified for short shot ranges, we determined the approximate flight trajectories of subcalibre projectiles for any angle of shot, including $90^{\circ}$ (i.e. a vertical shot). Figs. 7-9 show the dependencies between the range parameters and the subcalibre projectile's velocity versus flight time. In Fig. 7, the trajectories of hypersonic projectile flights for large angles of shooting (including vertical shots) are presented.

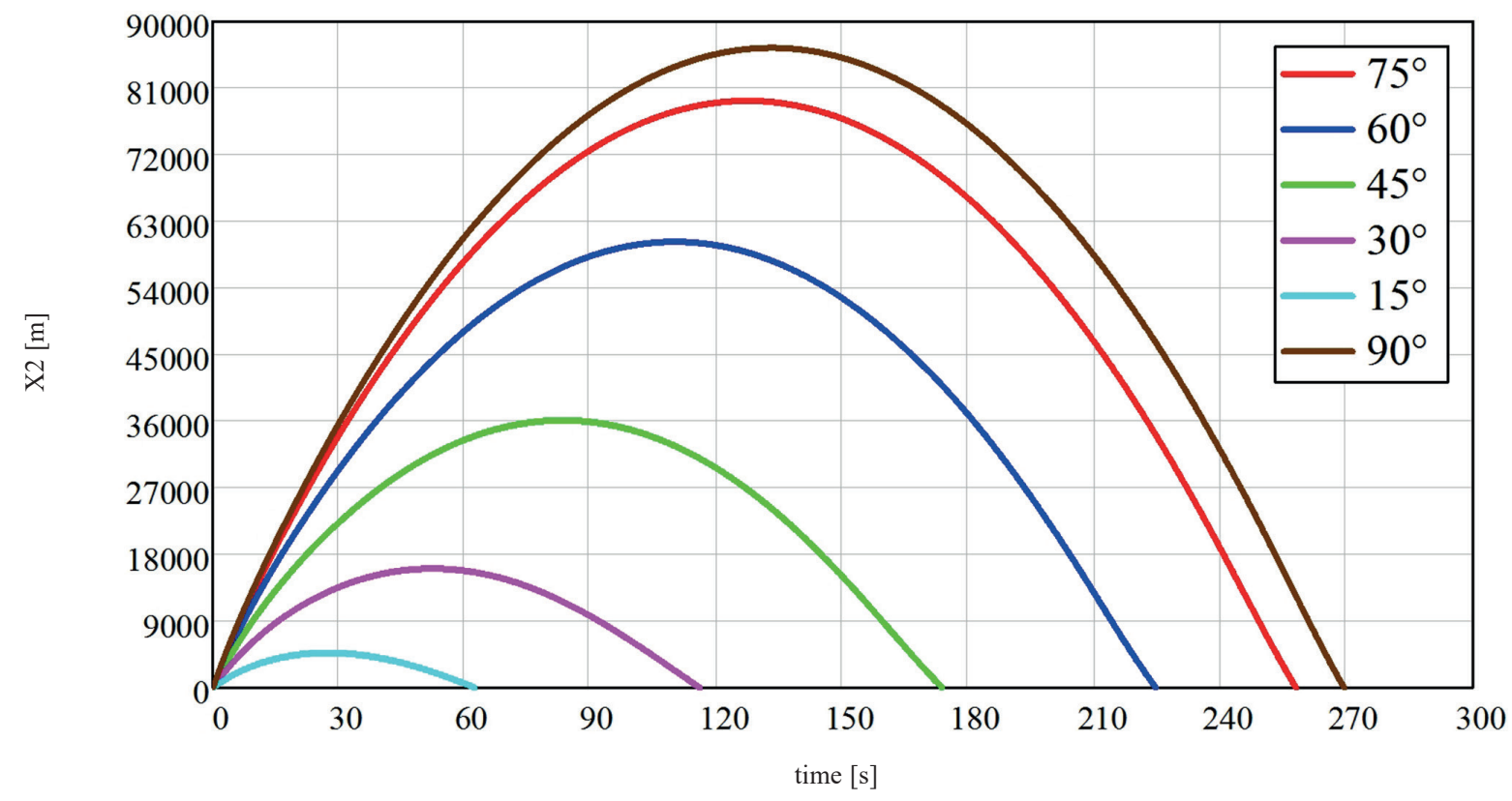

Fig. 7. Height of the projectile flight vs. time for large angles of shooting 


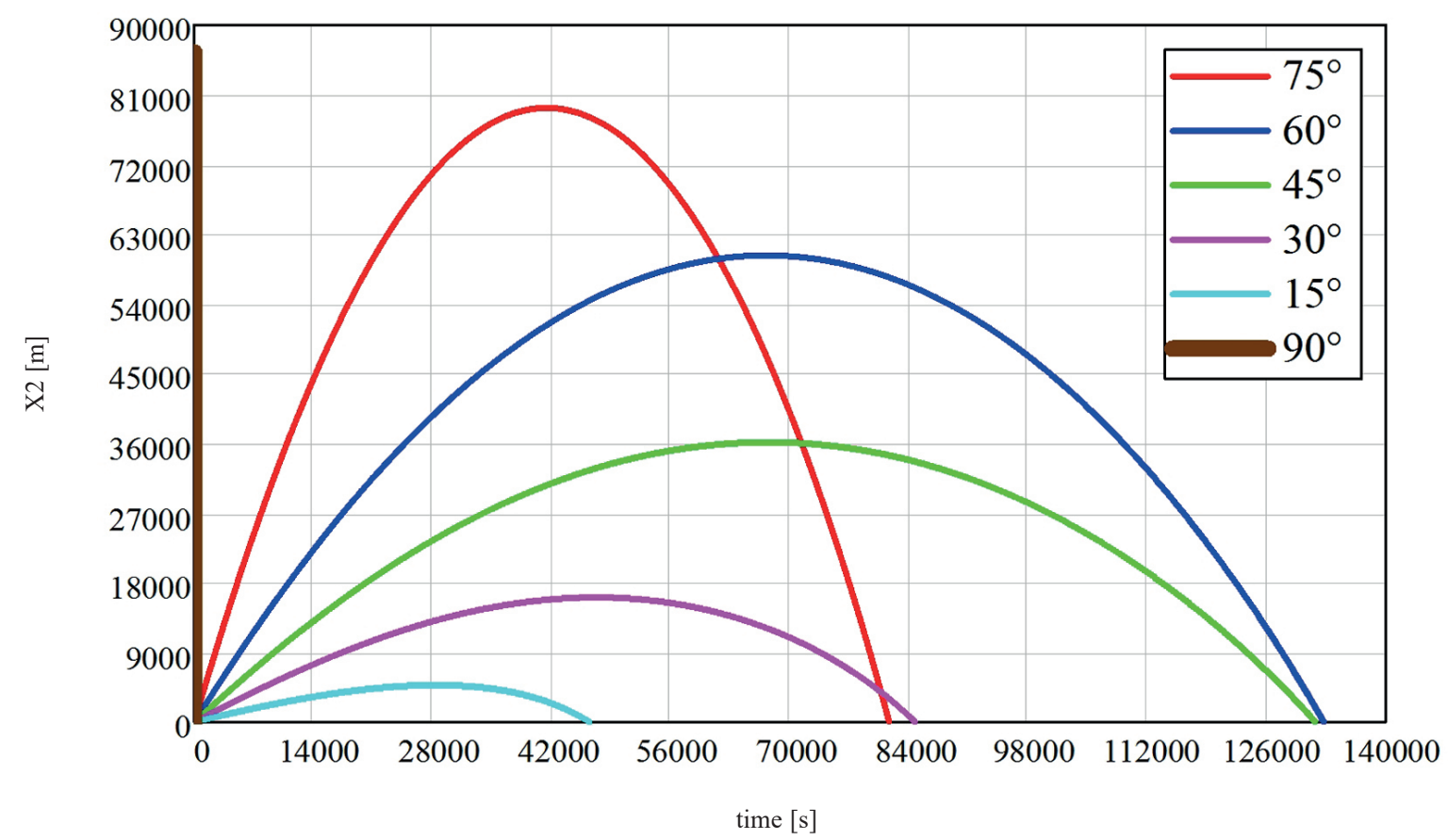

Fig. 8. Flight trajectories of projectiles for large angles of shooting

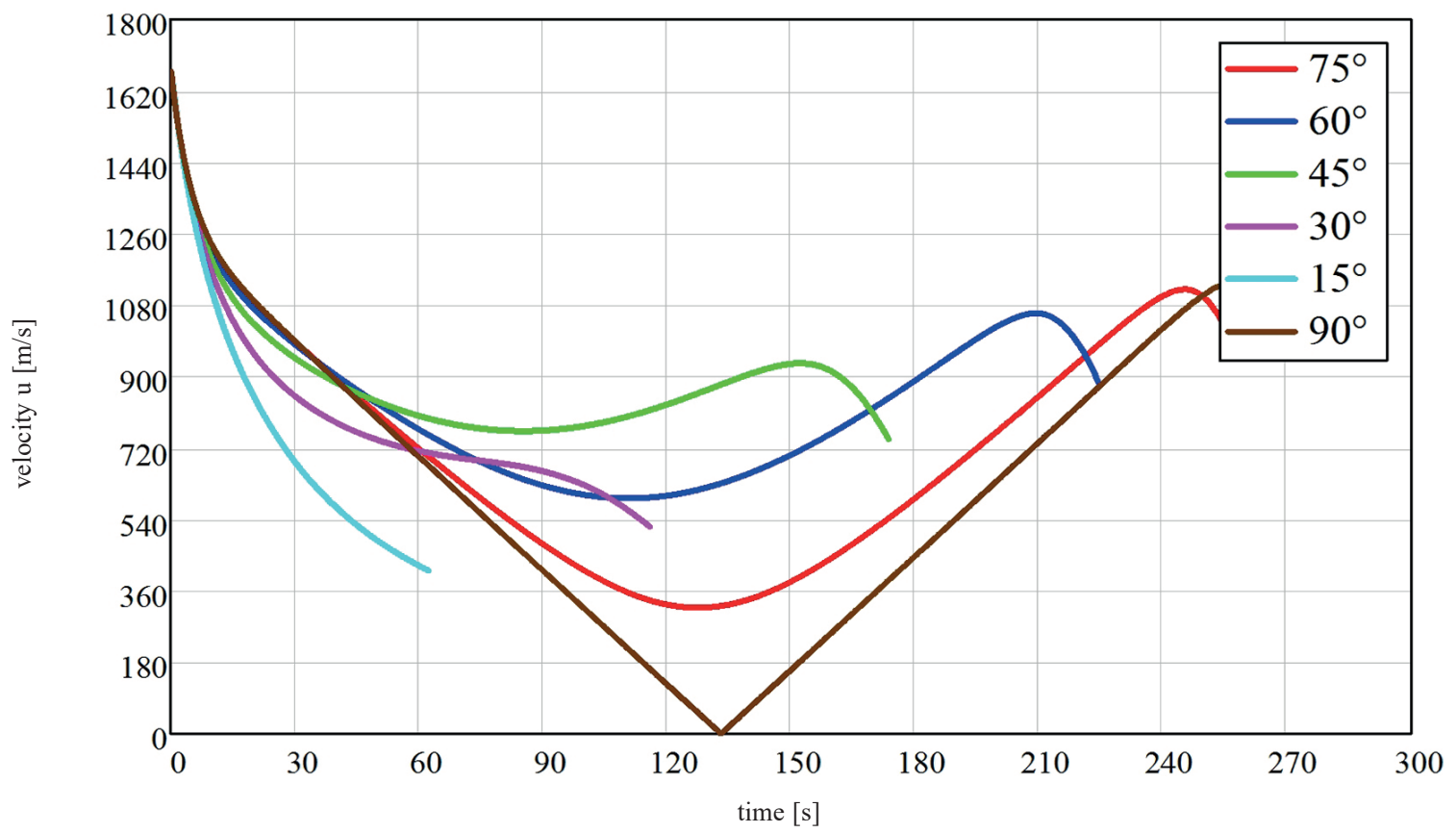

Fig. 9. Projectile velocity vs. time for large angles of shooting

\section{Conclusions}

We demonstrate the theoretical procedures for deter-mining the basic parameters of flight trajectory of hypersonic subcalibre projectiles, in view of assuring the firing safety. For this purpose, a mathematical-physical projectile model for $120 \mathrm{~mm}$ calibre ammunition of the determined initial parameters and a simulation program of projectile flight were developed.
The physical and mathematical models were designed according to the military standard NATO STANAG 4355. The simulation results were verified experimentally by measuring the velocity of the subcalibre projectile on the initial section of the flight trajectory equal to $2550 \mathrm{~m}$. The experimental results are in good agreement with those calculated using the developed model. For greater distances of shooting, the calculated results of the simulations are merely approximate, but they 
correctly give a qualitative picture of hypersonic projectile flight.

It results from our simulations that for small angles of shot $\left(0-7^{\circ}\right)$, the projectile velocity does not depend on the angle of shooting and a range of over $10 \mathrm{~km}$ is obtained for shooting angles over $1.5^{\circ}$. The maximum height and range of the subcalibre projectiles are nearly $90 \mathrm{~km}$ and more than $100 \mathrm{~km}$, respectively. The calculated range parameters of the subcalibre projectile determine the area of potential threat for the surroundings.

\section{REFERENCES}

[1] J.P. Paine, Self-Destructing Projectile, US Patent No. 4653405 A, 1987.

[2] J. Evans and A.B. Wardlaw, "Prediction of tubular projectile aero-dynamics using the ZEUS Euler code", J. Spacecraft and Rockets 26 (5), 314-321 (1989).

[3] R.L. McCoy, Modern Exterior Ballistics. The Launch and Flight Dynamics of Symmetric Projectiles, Schiffer Publishing, Atglen, PE, USA, 1999

[4] M. Magier, "The conception of the segmented kinetic energy penetrators for tank guns", J. Appl. Mechanics - Transactions of ASME 77 (5), 1-10 (2010).

[5] M. Magier, "The numerical optimization of the novel kinetic energy penetrator for tank guns", Proc. 26th Intern. Symp. on Ballistics 2, 1171-1080 (2011).
[6] M. Magier, "Experimental tests of subcalibre projectiles with segmented penetrators for tank guns", Proc. 27th Intern. Symp. on Ballistics 2, 1216-1225 (2013).

[7] J. Gacek, Modelling and Research of Dynamic Properties of Ballistic Objects, WAT, Warsaw, 1992, [in Polish].

[8] L. Baranowski, B. Gadomski, P. Majewski, and J. Szymonik, "Explicit ballistic M-model: a refinement of the implicit modified point mass trajectory model", Bull. Pol. Ac.: Tech. 64 (1), 81-89 (2016).

[9] L. Baranowski, "Effect of the mathematical model and integration step on the accuracy of the results of computation of artillery projectile flight parameters", Bull. Pol. Ac.: Tech. 61 (2), 475-484 (2013).

[10] B. Zygmunt and K. Motyl, "Computer assisted of a rocket flight modelling using MathCad programme", Mechanik 7, 973-980 (2011), [in Polish].

[11] B. Zygmunt, K. Motyl, B. Machowski, M. Makowski E. Olejniczak, and T. Rasztabiga, "Theoretical and experimental research of supersonic missile ballistics", Bull. Pol. Ac.: Tech. 63 (2), 229-233 (2015).

[12] J. Kokes, M. Costello, and J. Sahu, "Generating an aerodynamic model for projectile flight simulation using unsteady time accurate computational fluid dynamic results", WIT Transactions on Modelling and Simulation, Proc. 3rd Intern. Conference on Computational Ballistics, 31-54 (2007).

[13] NATO STANAG 4355 - The Modified Point Mass and Five Degrees of Freedom Trajectory Model, 3rd ed., 2009.

[14] PRODAS, Arrow Tech Associates, Inc. USA, 2008. 